\title{
Cavernous Haemangioma of the Tongue - A Rare Case Report
}

\author{
Sakshi Chawla ${ }^{1}$, Vidit Tripathi², Meenakshi Jain ${ }^{3}$, Yogesh Jain ${ }^{4}$ \\ 1, 2, 3,4 Department of ENT, Fortis Flt. Lt. Rajan Dhall Hospital, Vasant Kunj, New Delhi, India.
}

\section{INTRODUCTION}

Vascular anomalies include a wide range of tumours \& malformations. Among vascular anomalies, haemangioma is the most common. Haemangioma is considered as a hamartomatous lesion, \& half of these have a predilection for the head \& neck region but are rarely seen in the oral cavity. Haemangiomas are developmental vascular abnormalities. They are considered hamartomas rather than true neoplasms. More than $50 \%$ of these lesions occur in the head \& neck region mainly in the face, lips \& oral mucosa. The tongue is rarely involved. We are reporting the case of haemangioma of the tongue of a male child, discussing the diagnostic aspects \& treatment modalities of such a lesion \& emphasizing the role of CECT and Doppler Angiography especially in our case \& the short-term management in case of a complication such as in our case. The diagnosis of haemangioma of the tongue can be a little tricky as it sometimes does not present as a bluish lesion or a typical vascular swelling, so taking a biopsy in such cases may land up into complications such as tongue bite resulting in swelling of the tongue. A Colour Doppler Ultrasonography is an ideal first investigation in such cases but often not a very feasible option for the patients.

Hemangioma (Greek: Haima-blood; angeion-vessel; oma-tumour) is defined as a tumour of the dilated blood vessels. They are the most common vascular tumours of infancy \& childhood. ${ }^{1,2}$ Haemangiomas are of 2 types - capillary \& cavernous. They appear in the first month of life \& are characterized by a rapid proliferative phase \& slow involution, to near spontaneous resolution. Nearly $60-70 \%$ of the lesions are found in the head \& neck. ${ }^{3}$

Haemangiomas can also be described according to the vessel involved or flow type like arterial or arteriovenous type (high flow) or capillary or venous type (slow flow). ${ }^{4}$

We report a rare case of cavernous haemangioma of the tongue of a 3-year-old boy followed by a tongue bite.
Corresponding Author: Dr. Sakshi Chawla A-1/164 Safdarjung Enclave, New Delhi-110029, India.

E-mail: sakshich@gmail.com

DOI: $10.14260 /$ jemds/2022/62

How to Cite This Article:

Chawla S, Tripathi V, Jain $M$, et al. Cavernous haemangioma of the tongue: a rare case report. J Evolution Med Dent Sci 2022;11(01):322-325,

10.14260/jemds/2022/62

Submission 11-10-2021,

Peer Review 28-12-2021,

Acceptance 05-01-2022,

Published 31-01-2022.

Copyright (c) 2022 Sakshi Chawla et al. This is an open access article distributed under Creative Commons Attribution License [Attribution 4.0 International (CC BY 4.0)] 


\section{Case Report}

A 4-year-old boy presented in the ENT OPD with the chief complaint of certain lesions (fleshy papular) all over the tongue for 3 years. He had taken treatment for the same from multiple practitioners but with no relief. The parents also complained that the lesions used to swell on \& off. He was advised a biopsy of the tongue which was done under GA on $19 / 12 / 2018$. The child was admitted and a biopsy from the tongue was taken $\&$ he was discharged the same evening under satisfactory conditions.

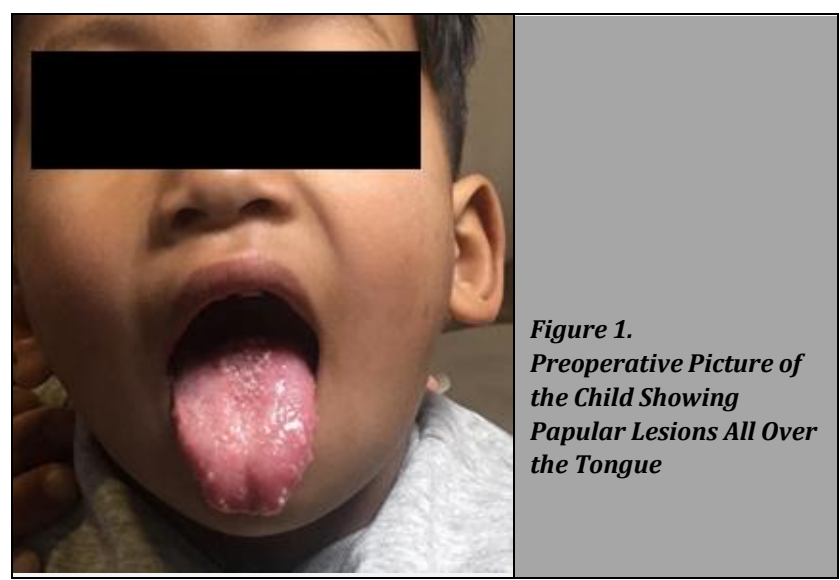

The next day the patient came to the hospital with a swelling of the tongue following a tongue bite. He was admitted again for observation. Treatment was started in accordance with the paediatric team.

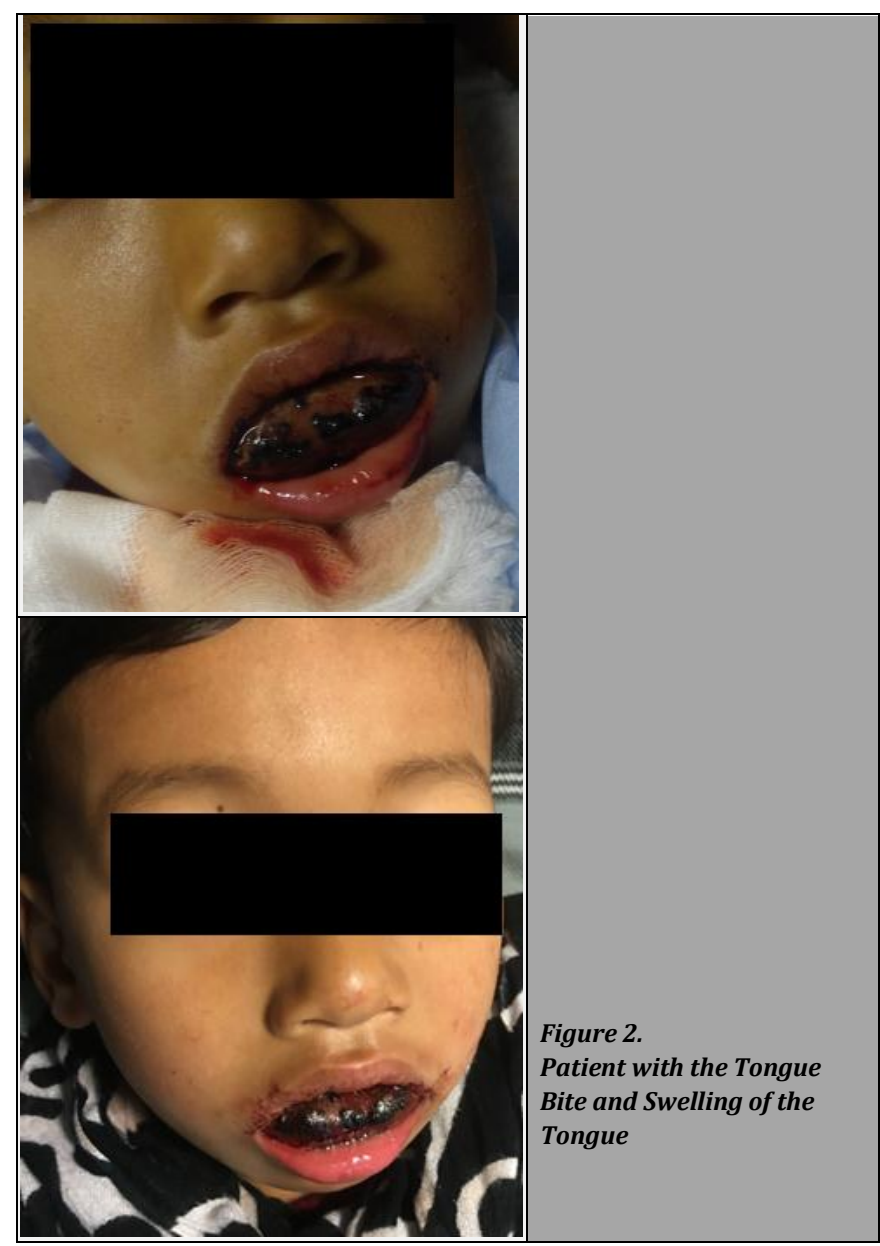

\section{RADIOLOGICAL FINDINGS}

A CT angiography of the neck was done which showed evidence of an enlarged tongue protruding out and occupying the whole of the oral cavity (macroglossia). The arterial phase showed a slight increase in the calibre of both the lingual arteries supplying the tongue - common trunk of the bilateral facial \& lingual arteries arising from the bilateral external carotid arteries. Venous phase showed heterogeneous enhancement of the tongue with few dilated vascular channels within the tongue, mild soft, tissue swelling was seen in B/L submandibular \& submental regions with fat stranding.

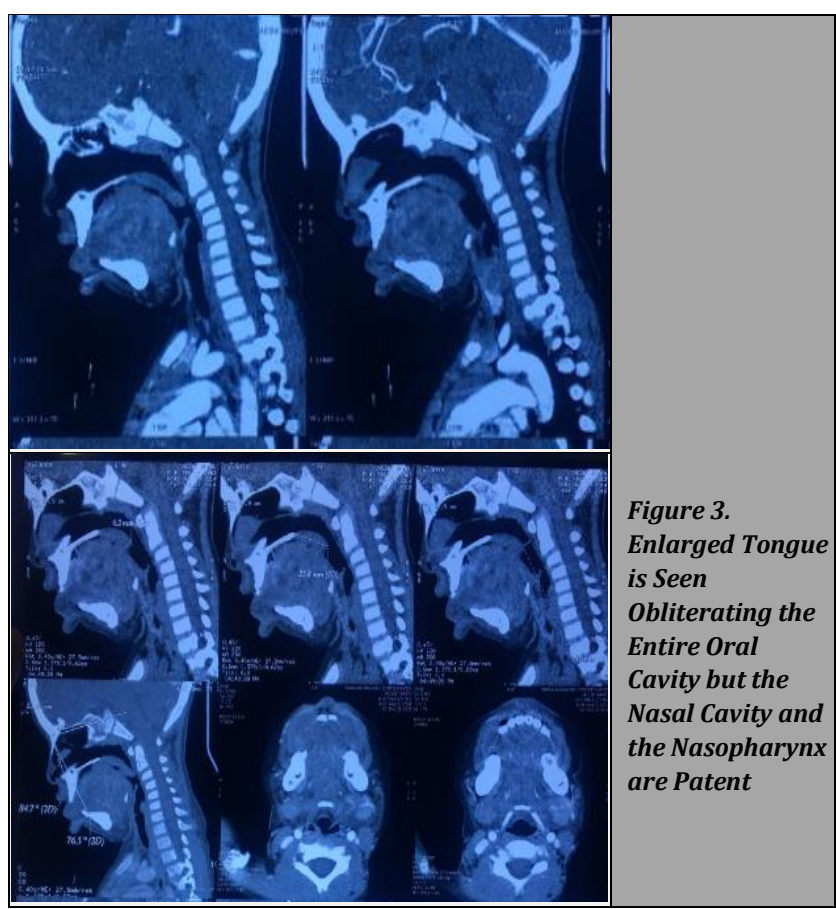

\section{HISTOPATHOLOGICAL FINDINGS}

Sections examined showed acanthosis \& papillomatosis of the squamous epithelial lining with the presence of a prominent dilated channel (cavernous/ lymphatic) lined by flattened cells in the subepithelial stroma \& partly in the skeletal muscle. There was regular maturation of the squamous epithelium. No significant koilocytic changes were seen. Mild to moderate inflammatory cell infiltrates comprising of lymphocytes, plasma cells, eosinophils \& polymorphs were seen in the vicinity of the dilated channels. No dysplasia or atypical cells were seen.

Interpretation Diagnosis: Vasoformative lesion in keeping with Haemangioma

The patient was nothing by mouth (NPO) throughout \& started on IV antibiotics, steroids, topical beta-blockers \& IV fluids with other supportive management. His vitals were stable throughout. There was no stridor, no respiratory distress or bleeding or infection. The child was discharged under stable condition for referral to Lok Nayak Hospital \& Maulana Azad Medical College. The TLC was 10800 at the time of discharge. 
The patient was managed conservatively with IV antibiotics, steroids, topical beta-blockers, IV fluids \& other supportive medication for another week \& the patient recovered completely \& was discharged.
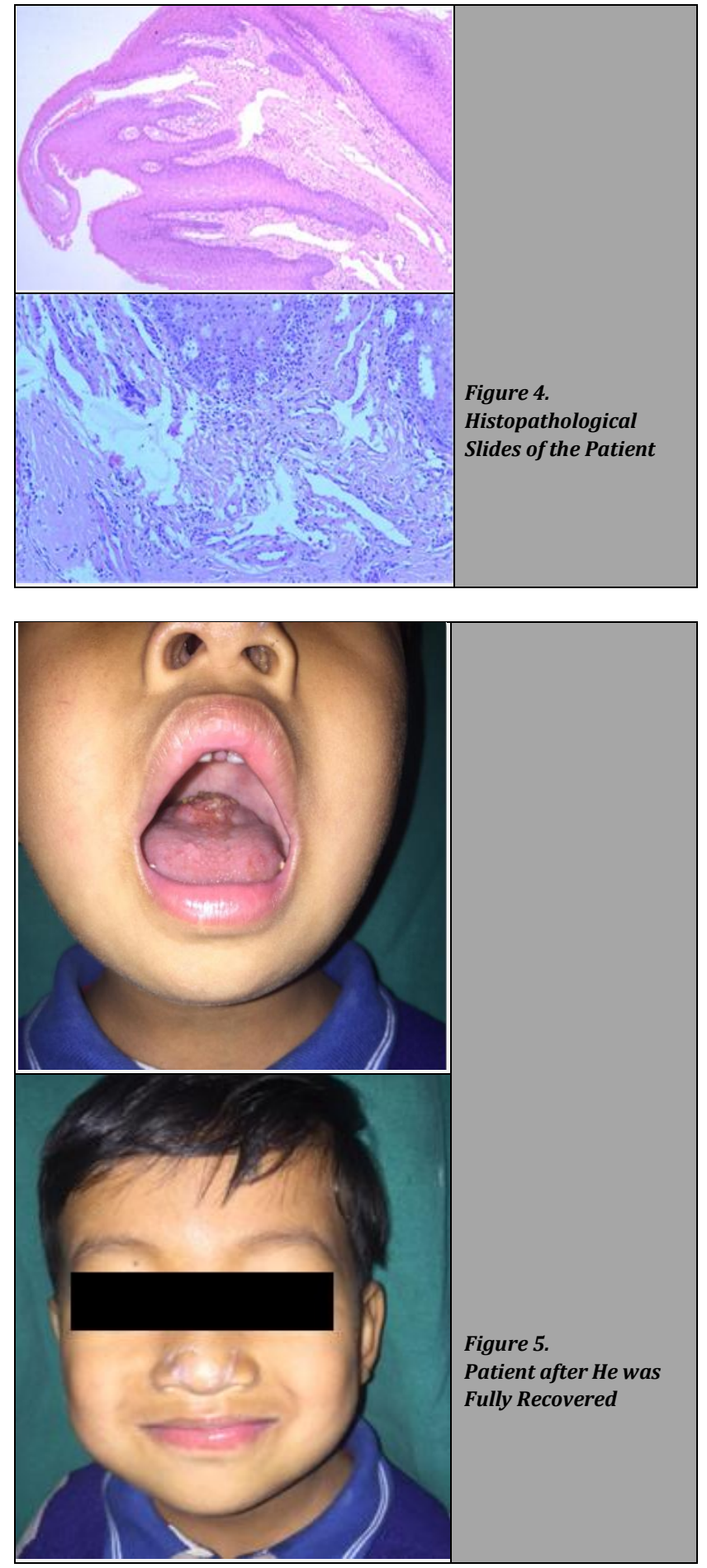

\section{DISCUSSION}

The term cavernous haemangioma has traditionally been applied when lesional vascular channels are considerably enlarged. 5 Cavernous haemangiomas consist of deep, irregular, dermal blood-filled channels. They are composed of tangles of thin-walled cavernous vessels or sinusoids that are separated by a scanty connective tissue stroma. ${ }^{6}$
With regard to the location and the number of lesions, a similarity with cases reported in the literature was observed, since approximately $80 \%$ of the patients present a single lesion, and the head and neck region is the most commonly affected. ${ }^{5}$ Haemangiomas show a notorious higher prevalence in females. The head and neck region is more commonly affected especially the face, oral mucosa, lips, tongue and trunk. $^{7}$

Clinically haemangiomas are characterized as soft, smooth or lobulated, sessile or pedunculated and may be seen in any size from a few millimetres to several centimetres. The colour of the lesion ranges from pink to red purple and tumour blanches on the application of pressure, and haemorrhage may occur either spontaneously or after minor trauma. They are generally painless. ${ }^{6}$

Although haemangioma is considered as one of the most common soft tissue tumours of the head and neck, it is relatively rare in the oral cavity and uncommonly encountered by clinicians. Radiographic imaging is indicated preoperatively in selected cases where large lesions may impinge on vital anatomical structures, such as the facial nerve or orbit. Computed tomography (CT) and magnetic resonance imaging (MRI) can also be used for volumetric analysis of haemangiomas and vascular malformations. ${ }^{7}$ Imaging resources can also be useful in both diagnostic differentiation and analysis of lesion that features with regard to its size, extension, and location, as well as for following up of lesions treated under systemic therapy. Differential diagnosis between vascular and non-vascular lesions is based on clinical findings and semiotic manoeuvres, such as diascopy or glass slide pressure. 5 Baba and Kato reported a case of haemangioma with phleboliths in the floor of the mouth and Doppler ultrasonography, CT, MRI were used to diagnose the lesion. ${ }^{3}$

Management of haemangioma depends on a variety of factors, and the truest haemangioma requires no intervention. However, 10-20\% of them require treatment because of the size, exact location, stages of growth or regeneration. There are many treatment modalities reported in the literature for head and neck haemangiomas, including wait and watch policy, for spontaneous involution, intralesional and systemic corticosteroid treatment, embolization, excision, electrolysis and thermocautery, immunomodulatory therapy with interferon alfa-2a, and laser photocoagulation. ${ }^{8}$ Recent interest has centred on the interstitial delivery of laser energy to photocoagulate vascular lesions. Currently, sclerotherapy is employed largely because of its efficiency and ability to conserve the surrounding tissues. 7 Among the sclerosing agents available, excellent results have been reported for sodium morrhuate, sodium tetradecyl sulfate, polidocanol and ethanolamine oleate, and hypertonic glucose solution. ${ }^{3,5}$

A growing haemangioma can be treated effectively by systemic drug therapy, sclerotherapy, laser therapy or combined therapy. Transcutaneous and contact applications of laser energy have been studied with the argon and Nd: YAG lasers while the 585-nm flashlamp - pulsed dye laser can be used in cutaneous and subcutaneous haemangiomas. ${ }^{9}$ Vesnaver applied photocoagulation with interstitial Nd: YAG laser in 111 patients with vascular lesions in the head and neck region and he concluded that, Nd: YAG laser is a safe and effective tool for treating vascular lesions. ${ }^{10}$ 
Haemangiomas of the tongue are rare lesions that can cause distressing problems to the patients, producing cosmetic deformity, recurrent haemorrhage, and functional problems with speaking, mastication, and deglutition. The treatment depends on lesion location, size and evolution stage, and the patient's age. Due to its side effects, radiotherapy and chemotherapy would not be suitable as a treatment choice for tongue lesions. Swallowing, chewing, and speaking function disabilities were seen in the cases where $\mathrm{CO}_{2}$ laser was applied. 3,11

Surgery is usually indicated when there is no response to systemic treatments, or even for aesthetic reasons, being performed as a simple excision in combination or not with plastic surgery. Conservative or further aggressive forms of treatment may be tried for the haemangiomas of the tongue. Both treatment methods have disadvantages. In conservative treatment, recurrence may be frequent. On the other hand, aggressive treatment could also cause function loss. 6,7

However, the results of cryotherapy have been reported to have high success rates. Kutluhan used plasma knife surgery for excision of haemangioma of the tongue. ${ }^{12}$

Financial or other competing interests: None.

Disclosure forms provided by the authors are available with the full text of this article at jemds.com.

\section{REFERENCES}

[1] Maaita JK. Oral tumors in children: a review. J Clin Pediatr Dent 2000;24(2):133-5.

[2] Tanaka N, Murata A, Yamaguchi A, et al. Clinical feature \& management of oral \& maxillofacial tumors in children. Oral Surg Oral Med Oral Pathol Oral Radiol Endod 1999;88(1):11-5.
[3] Okoje VN, Alonge TO, Olusanya AA. Intra-tumoral ligation \& the injection of sclerosant in the treatment of lingual cavernous haemangioma. Niger J Med 2011;20(1):172-5.

[4] Greenberg M, Glick M, Ship JA, eds. Burkett's oral medicine, diagnosis \& treatment. $11^{\text {th }}$ edn. Hamilton: BC Decker Inc. 2008:490-1.

[5] De Avila ED, de Molon RS, Neto NC, et al. Lip cavernous haemangioma in a young child. Braz Dent J 2010;21(4):370-4.

[6] Slaba S, Braidy C, Sader RB, et al. Giant venous malformation of the tongue: the value of surgiflo. J Mal Vasc 2010;35(3):197-201.

[7] Bonet-Coloma C, Mínguez-Martínez I, Palma-Carrió C, et al. Clinical characteristics, treatment and outcome of 28 oral haemangiomas in paediatric patients. Med Oral Patol Oral Cir Bucal 2011;16(1):e19-22.

[8] Atkins JH, Mandel JE, Mirza N. Laser ablation of a large tongue haemangioma with remifentanil analgosedation in the ORL endoscopy suite. ORL J Otorhinolaryngol Relat Spec 2011;73(3):166-9.

[9] Zheng JW, Wang YA, Zhou GY, et al. Head and neck haemangiomas: How and when to treat. Shanghai Kou Qiang Yi Xue 2007;16(4):337-42.

[10] Vesnaver A, Dovsak DA. Treatment of vascular lesions in the head and neck using $\mathrm{Nd}$ : YAG laser. J Craniomaxillofac Surg. 2006;34(1):17-24.

[11] Qureshi SS, Chaukar DA, Pathak KA, et al. Haemangioma of base of tongue. Indian J Cancer 2004;41(4):181-3.

[12] Kutluhan A, Bozdemir K, Ugras S. The treatment of tongue haemangioma by plasma knife surgery. Singapore Med J 2008;49(11):e312-4. 